\title{
Chronic dietary exposure to pyrolytic and petrogenic mixtures of PAHs causes physiological disruption in zebrafish - part I: Survival and growth
}

\author{
Caroline Vignet ${ }^{1}$, Karyn Le Menach ${ }^{2}$, David Mazurais ${ }^{3}$, Julie Lucas ${ }^{1,4}$, Prescilla Perrichon ${ }^{1}$, \\ Florane Le Bihanic ${ }^{2}$, Marie-Hélène Devier ${ }^{2}$, Laura Lyphout ${ }^{1,5}$, Laura Frère ${ }^{5}$, Marie-Laure Bégout ${ }^{5}$, \\ José-Luis Zambonino-Infante ${ }^{3}$, Hélène Budzinski ${ }^{2}$, Xavier Cousin ${ }^{1,6, *}$
}

\footnotetext{
${ }^{1}$ Laboratoire d'Ecotoxicologie, Ifremer, Place Gaby Coll, BP7, 17137, L'Houmeau, France

${ }^{2}$ University of Bordeaux 1, EPOC, UMR CNRS 5805, 33405, Talence, France

${ }^{3}$ Unit of Functional Physiology of Marine Organisms, Ifremer, UMR 6539 LEMAR, 29280, Plouzané, France

${ }^{4}$ UMR 7266 Littoral Environnement Sociétés (LIENSs), Institut du Littoral et de l'Environnement, 2 rue Olympe de Gouges, 17000, La Rochelle, France

${ }_{5}^{5}$ Laboratoire Ressources Halieutiques, Ifremer, Place Gaby Coll, BP7, 17137, L'Houmeau, France

${ }^{6}$ INRA LPGP, Campus de Beaulieu, 35042, Rennes, France
}

*: Corresponding author : Xavier Cousin, email address : xcousin@ifremer.fr

\begin{abstract}
:
The release of polycyclic aromatic hydrocarbons (PAHs) into the environment has increased very substantially over the last decades leading to high concentrations in sediments of contaminated areas. To evaluate the consequences of long-term chronic exposure to PAHs, zebrafish were exposed, from their first meal at 5 days post fertilisation until they became reproducing adults, to diets spiked with three $\mathrm{PAH}$ fractions at three environmentally relevant concentrations with the medium concentration being in the range of 4.6-6.7 $\mathrm{mg} \mathrm{g}^{-1}$ for total quantified PAHs including the 16 US-EPA indicator PAHs and alkylated derivatives. The fractions used were representative of PAHs of pyrolytic (PY) origin or of two different oils of differing compositions, a heavy fuel (HO) and a light crude oil (LO). Fish growth was inhibited by all PAH fractions and the effects were sex specific: as determined with 9-month-old adults, exposure to the highest PY inhibited growth of females; exposure to the highest $\mathrm{HO}$ and LO inhibited growth of males; also, the highest $\mathrm{HO}$ dramatically reduced survival. Morphological analysis indicated a disruption of jaw growth in larvae and malformations in adults. Intestinal and pancreatic enzyme activities were abnormal in 2-month-old exposed fish. These effects may contribute to poor growth. Finally, our results indicate that PAH mixtures of different compositions, representative of situations encountered in the wild, can promote lethal and sublethal effects which are likely to be detrimental for fish recruitment.
\end{abstract}

Keywords: Danio rerio ; Life cycle ; Polycyclic aromatic hydrocarbon ; Heavy oil ; Light crude oil ; Alkylated PAH ; Jaw ; Digestion 


\section{Introduction}

Xenobiotics are increasingly being released into the environment as a result of human activities. The compounds of one particular group of xenobiotics, persistent organic pollutants (POPs) persist in the environment, have lipophilic properties and are very stable chemically, making the bioaccumulation of these molecules highly likely. Aquatic compartments, including sediment, often constitute the ultimate reservoir of these compounds, so fish may be exposed to POPs at various stages in their lives.

Polycyclic aromatic hydrocarbons (PAHs) constitute a large and diverse family of POPs formed by the association of several aromatic rings. This family of molecules also includes $\mathrm{PAH}$ derivatives with alkyl, nitrogen, sulfur or oxygen substitutions. PAHs and their derivatives are produced during the combustion of organic matter (pyrolytic PAHs) and are present in oils (petrogenic PAHs). Pyrolytic PAHs are released into the atmosphere, leading to their deposition on water and soil. PAHs deposited on soil can enter water compartments through runoff. Petrogenic PAHs may be discharged directly into water as a result of oil spills or naval or offshore oil drilling activities (Latimer \& Zheng 2003). PAHs are also introduced into the environment through natural processes, such as oil leaks or diagenesis. In all cases, PAHs are present in the form of complex mixtures containing large amounts of individual PAHs and derivatives. The composition of mixtures of PAHs depends on their origin. Pyrolytic mixtures contain a high proportion of heavy PAHs, such as benzo[a]pyrene (BaP), and few alkylated PAHs, whereas petrogenic mixtures contain a smaller proportion of heavy PAHs, with a higher proportion of light PAHs and larger amounts of alkylated PAHs (Benlahcen et al. 1997, Budzinski et al. 1997, Latimer \& Zheng 2003, Neff 1979, Yunker et al. 2002). The release of PAHs into the environment has increased in recent decades (Eisler 1987, Shen et al. 2013, Zhang \& Tao 2009). Indeed, monitoring networks have documented $\mathrm{PAH}$ concentrations of up to $50 \mu \mathrm{g} \cdot \mathrm{g}^{-1}$ dry weight (dw) in sediment from various affected aquatic ecosystems, although the concentrations in highly contaminated areas were mostly found to be in the $10 \mu \mathrm{g} . \mathrm{g}^{-1}$ range (Baumard et al. 1998, Benlahcen et al. 1997, Cachot et al. 2006, Johnson et al. 2007, Varanasi et al. 1993, Yanagida et al. 2012). The concentration of $\mathrm{PAHs}$ in the biota depends on the concentration of these molecules in the immediate surroundings and trophic level. For example, the total concentration of the 16 PAHs used as indicators by the US Environmental Protection Agency (US-EPA) in the copepod Eurytemora affinis in the Seine Estuary has been reported to be in the $165-3866 \mathrm{ng} \cdot \mathrm{g}^{-1} \mathrm{dw}$ range (Cailleaud et al. 2007) and, in mussels, this concentration may reach $1600 \mathrm{ng} \cdot \mathrm{g}^{-1} \mathrm{dw}$ (Le Goff et al. 2006). In cases of acute accidental exposure, the concentration in mussels may be even higher, with values reaching $3000 \mathrm{ng} \cdot \mathrm{g}^{-1} \mathrm{dw}$ reported after the Erika oil spill (Jeanneret et al. 2002) and of $14350 \mathrm{ng} . \mathrm{g}^{-1} \mathrm{dw}$ recorded after the Exxon Valdez oil spill (Payne et al. 2008). PAHs accumulate in animals located at lower levels of the food chain because they are poorly metabolized in these species. Food is thus an important source of exposure, as demonstrated by the high concentrations of PAHs found in the stomachs of fish caught in contaminated areas (Johnson et al. 2007, Varanasi et al. 1993, Yanagida et al. 2012).

There is growing evidence to suggest that POPs can act as neurotoxicants, particularly in cases of early exposure (Ottinger et al. 2013, Scott \& Sloman 2004). Only a few studies have described the behavioral disruptions following PAH exposure in fish. In most cases, this was achieved by waterbone exposure of juveniles to single compound (Almeida et al. 2012, Correia et al. 2007, Goncalves et al. 2008, Gravato \& Guilhermino 2009, Oliveira et al. 2012). One study also reported additive effects for a mixture of three PAHs (Goncalves et al. 2008). These studies have generally concluded that PAHs cause lethargy, resulting in a decrease in the swimming activities of exposed fish. 
Early stages are considered to be more sensitive than later stages, but the number of studies focusing on early stages (embryo-larval stage) is even smaller. For example, brief exposure of medaka embryos to sediment spiked with benzo[a]anthracene has been shown to reduce larval activity after a photomotor challenge in medaka (Le Bihanic, personal communication). Finally, the exposure of Pacific herring eggs to weathered oil has several adverse effects, including a decrease in the ability of the larvae to swim (Carls et al. 1999). We have shown that the brief exposure (from 4 to $96 \mathrm{~h}$ post fertilization) of zebrafish embryos to a mixture of benzo[a]pyrene, pyrene and phenanthrene leads to lower levels of locomotor activity and/or the induction of anxiety-like behavior in adults (Vignet et al. 2014a). These findings are consistent with observations showing that exposure to PAHs is associated with several types of neurobehavioral disruption, including anxiety and attention disorders, in humans and rodents (Bouayed et al. 2009, Edwards et al. 2010, Jedrychowski et al. 2003, Perera et al. 2012, Saunders et al. 2001, 2003, Tang et al. 2008, Xia et al. 2011). It has also recently been shown that perinatal exposure to a mixture of $16 \mathrm{PAHs}$ induces anxiety-related behavior in adult rats (Crépeaux et al. 2012, 2013).

Quantitative behavior analysis is now considered to be a good indicator in studies of pharmacology, toxicology, ecotoxicology and in cognition or neurobiology (Ali et al. 2011a, Ali et al. 2011b, Champagne et al. 2010). The use of model fish species, such as medaka and zebrafish, has developed exponentially over the last decade, and the use of these species in this context is now widely accepted (Champagne et al. 2010, Creton 2009, Norton \& Bally-Cuif 2010, Steenbergen et al. 2011). Studies of fish behavior as a means of investigating the neurotoxic effects of compounds and the underlying mechanisms of toxicity are becoming increasingly common. Fish have been used as models of human disorders in studies on compounds such as alcohol (Gerlai et al. 2000, MacPhail et al. 2009) and for the testing of drugs to treat anxiety (Champagne et al. 2010, Egan et al. 2009, Maximino et al. 2010). In the particular context of ecotoxicology, individual responses correspond to the interface between ecological factors and toxicity mechanisms, making individual behavior a particularly relevant and integrative indicator of the effects of pollutants (Bailey et al. 2013, Hinton et al. 2005, MacPhail et al. 2009).

We report here the effects of long-term dietary exposure to three environmental mixtures of $\mathrm{PAHs}$ in zebrafish, in a dose-response study with three concentrations. Fish were fed diets spiked with mixtures approximating relevant environmental concentrations, from their first meal at 5 days post fertilization (dpf). We analyzed several behavioral traits, including locomotion, exploration and anxiety, successively in two-month-old juveniles and six-monthold adults. In addition to measuring behavioral toxicity and evaluating the neurotoxicity of $\mathrm{PAHs}$ in a model species, we also evaluated the potential ecological consequences for fish populations.

\section{Materials and Methods}

\subsection{Preparation of PAH-contaminated diets}

Three aromatic fractions were used for exposure experiments: i) a pyrolytic fraction (PY) extracted from sediments collected from a polluted site of the Seine Estuary (Oissel, France) and ii) two petrogenic fractions obtained from Erika fuel (heavy oil; HO) and Arabian Light crude oil (LO). PAHs were extracted as previously described (Cachot et al. 2006). Zebrafish were exposed from their first meal (at $5 \mathrm{dpf}$ ) onward, through spiked food pellets. The food pellets obtained from the supplier were $0.5 \mathrm{~mm}$ in diameter (INICIO Plus 0.5, Biomar, France); these pellets were ground and used to prepare age-appropriate food pellets of four sizes: $\leq 125 \mu \mathrm{m}, 125-315 \mu \mathrm{m}$, 
315-500 $\mu \mathrm{m}$ and $\geq 500 \mu \mathrm{m}$ (Vignet et al. 2014b). Three concentrations, 0.3X, 1X and 3X, were used, with the $1 \mathrm{X}$ concentration corresponding to the $\Sigma[16 \mathrm{EPA} \mathrm{PAH}]$ at $5 \mu \mathrm{g} \cdot \mathrm{g}^{-1} \mathrm{dw}$ food, representative of the concentrations found in mollusks in the Seine Estuary. The names of the diets indicate the origin of the fraction and its concentration. For example, the $1 \mathrm{X}$ pyrolytic fraction diet was named PY-1X. For each exposure, a control treatment was included, corresponding to the plain food treated as for the spiked food with dichloromethane, the carrier solvent used for PAH spiking.

\subsection{Fish exposure}

This study was conducted with the approval of the French Animal Care Committee under the official license held by M.-L. Bégout (17-010).

We used the zebrafish wild-type TU strain (ZFIN ID: 76 ZDB-GENO-990623-3), which was established at our platform (PEP - http://wwz.ffremer.fr/pep) six years ago from large batches of individuals originating from the Amagen platform (Gif/Yvette, France) and the Pasteur Institute fish facility (Paris, France). The exposure procedures are described in detail in the article by Vignet et al. (2014b). Briefly, eggs were obtained by the random pairwise mating of zebrafish placed together in spawning boxes (AquaSchwarz, Germany) overnight. Eggs were collected the next morning and the rate of fertilization was assessed within two hours of collection: only spawns with a fertilization rate greater than $80 \%$ were retained. We ensured that incubation conditions were as homogeneous as possible, by mixing at least five spawns and then randomly sampling 50 embryos and transferring them to as many Petri dishes as required for the planned number of treatments. Exposure experiments with PY, HO and LO were carried out successively (PY in year one of the project, $\mathrm{HO}$ and LO in year two, see details in Vignet et al. (2014b)) and all exposures were performed in triplicate. Embryos and larvae were maintained at $28^{\circ} \mathrm{C}$, in clean medium, in Petri dishes in an incubator subjected to the same photoperiod as for adults. From $5 \mathrm{dpf}$ onwards, each replicate were reared in separate 1-liter tanks. After 12 days, they were transferred to 10-liter tanks in a flow through system with water renewal, the daily rate of which was increased with age, reaching $40 \%$ after one month. Standard water quality and rearing methods were used (Lawrence 2007, Vignet et al. 2014b). From $5 \mathrm{dpf}$ onwards, the fish were fed twice daily with sizeadapted spiked pellets and once daily with plain Artemia nauplii. The fish were allowed ad libitum access to the food pellets from $5 \mathrm{dpf}$ until the first biometric measurements were taken: at 2 months post-fertilization (mpf) for $\mathrm{HO}$ and LO and at $3 \mathrm{mpf}$ for PY. Thereafter, the quantity of food provided was equivalent to $2 \%$ of the biomass in each tank, with the exception of the PY-spiked food, for which we provided $\sim 5 \%$ of the biomass in the tank until $3 \mathrm{mpf}$ when we decreased to $2 \%$. Rations were adapted on a monthly basis, following biometric measurements. This led to differences in growth between the control fish, which were heavier and longer for PY (at $6 \mathrm{mpf}$, body mass $(\mathrm{mg}): 707 \pm 22$; body length $(\mathrm{mm}): 31.1$ \pm 0.3 ) than for $\mathrm{HO}$ and $\mathrm{LO}$ (body mass $(\mathrm{mg})$ : $\mathrm{HO}=265 \pm 7$; $\mathrm{LO}=246 \pm 6$; body length $(\mathrm{mm})$ : $\mathrm{HO}=25.2 \pm 0.2$; LO $=24.3 \pm 0.2$ ) as described in detail in Vignet et al. (2014b). These differences in body size may partly account for the differences in behavioral responses observed between control PY and control HO/LO fish.

\subsection{Behavioral experiments}

Behavioral experiments were performed with two-month-old undifferentiated juveniles and six-month-old adult males and female (in equal proportions, except for HO-3X, for which it was not possible to distinguish between the sexes on the basis of phenotype). Different sets of animals were used for each behavioral test, except for the photomotor response in adults, which was coupled with the 24-h swimming activity test, and the maze test, which was coupled with the novel tank test, these tests being performed consecutively on the same day 
(see below for the detailed protocol). HO-3X fish were not tested at the age of six months in the Z-maze and novel tank tests, because of their low survival (Larcher et al. In revision; Vignet et al. 2014b). Tests were carried out in a dedicated room maintained at $27^{\circ} \mathrm{C} \pm 1^{\circ} \mathrm{C}$, with a 14:10 photoperiod synchronized with that of the rearing room so as to minimize unwanted correlated effects. The light was switched on at 08:30 and there were no twilight transition periods.

\subsection{4-h swimming activity in adults}

At each session and for each fraction, six-month old fish exposed to each concentration were randomly placed in 3-liter tanks (24.5 × $15 \times 13.5 \mathrm{~cm}$, AquaBox® 3, AquaSchwartz, Göttingen, Germany) filled with 1.5 liters of system water, to avoid tank position and session bias. The 12 tanks (3 fish per concentration) were isolated from neighboring tanks by opaque walls. They were placed on top of an infrared apparatus (IR floor $1 \times 1 \mathrm{~m}$, Noldus, The Netherlands). During the day, the room was lit with two LED spotlights (LED Technology Master LEDSPOT 16W 2700K, illumination of 30 lux near the tanks). During the night or dark period, the spotlights were turned off and infrared light from the floor was used to record fish movements (illumination $<1$ lux near the tanks). Fish were placed in the tanks at 17:00 on the day before the experiment, to allow them to acclimate overnight. Video recordings began the next day at 12:30 and lasted $24 \mathrm{~h}$. We tested 12 fish for each concentration. We ran four sessions for each fraction (PY, HO and LO) and the water was changed after each session.

\subsection{Photomotor response in juveniles and adults}

We used the same setup to monitor photomotor responses, as an indicator of complex phenotypes of stress and anxiety (Vignet et al. 2013). We recorded swimming activity for $1 \mathrm{~h}$ (Light on-1) and then challenged the fish by subjecting them to a sudden dark period (15min, Light off), continuing the video recordings for an additional $1.5 \mathrm{~h}$ (Light on-2). The photomotor response was monitored after one night of acclimation, beginning at 12:30 for two-month-old fish or at the end of the 24-h recording for six-month-old fish. For both tests, the dependent variables measured were swimming path length (distance traveled; $\mathrm{cm}$ ) and time spent immobile (time; s). We tested 12 fish for each concentration. We ran four sessions for each fraction (PY, HO and LO) and the water was changed after each session.

\subsection{Exploration of a new environment- maze challenges}

In addition to providing information about the ability of fish to explore their environment, the swimming characteristics recorded during exploration provide information about the ways in which fish cope with this novel environment. Two experimental setups were used: maze challenges (a T-maze or a Z-maze) and a novel tank challenge.

The T-maze was used for PY fish (in year one of the project). This maze was adapted slightly from that described by Ninkovic and Bailly-Cuif (2006) and comprised a shallow area, with a water depth of $5 \mathrm{~cm}$, consisting of the stem of the $T(46 \mathrm{~cm}$ long), and its two arms (one leading to a deep area and one in the opposite direction). The total length of the arms was 66 $\mathrm{cm}$. The deep area was $15 \mathrm{~cm}$ deep (water depth of $10 \mathrm{~cm}$ ), $23 \mathrm{~cm}$ wide and $23 \mathrm{~cm}$ long, and it contained marbles and plastic grass, and was therefore considered to be a favorable area (Ninkovic \& Bally-Cuif 2006). Fish were individually transferred into a 1-liter aquarium at 16:00 on Day 1 and were challenged on Day 2, between 9:00 and 11:00. Fish were placed in the start area of the maze and their swimming characteristics were recorded for 5 minutes. We tested 12 fish per concentration and the dependent variables measured were time to the first exit from start area; in s), the time spent in each area (start, shallow, deep; in s), 
individual success or failure to reach the deep area and time to first entry into the deep area (s).

For the $\mathrm{HO}$ and LO mixtures, in year two of the project, a Z-maze $(70 \times 45 \times 15 \mathrm{~cm})$ adapted from that described by Chapman et al. (2010) was preferred over the T maze. We decided to use the Z-maze for these experiments because it is more suitable than the T-maze for the evaluation of exploration (Chapman et al. 2010), the T-maze being more appropriate for assessments of learning, which was not the main focus of this experiment. The Z-maze consisted of a refuge zone and four arms (see figure 1 in Chapman et al. 2010). Each arm was divided virtually into four quarters of equal size, referred to as quadrants. The maze thus consisted of 16 quadrants. Fish were individually placed in a 1-liter aquarium at 16:00 on Day 1 and challenged on Day 2, between 9:00 and 11:00. Fish were introduced into the refuge zone (equivalent to 3 quadrants, covered with a black slab and ending in a sliding door). The start area thus consisted of these three covered quadrants and the adjacent one. The next two arms formed the close area (close to the refuge zone) and the last two arms formed the distant area. The fish were left for two minutes in the refuge zone and the door was then opened. Fish activity was recorded in the five minutes following the first excursion of the fish from the refuge zone (detection in the first quadrant of the close area). The variables measured were the time taken to leave the refuge (time to first exit from the refuge zone; in s), the time spent in each area (start, close, distant; s) during the trial and individual success or failure to reach quadrant 16 (the farthest from the refuge zone). We also determined the number of quadrants into which the fish ventured within the maze (16 indicating that the fish reached the end of the maze), as an index of individual tendency to explore (Chapman et al. 2010). We converted these data into proportions for statistical analysis. We tested 12 fish per fraction and per concentration.

\subsection{Exploration of a new environment- the novel tank challenge}

The novel tank challenge was performed from 14:00 to 16:00 on the same day as the maze exploration test (which was performed from 9:00-11:00). Between tests, the fish were individually kept in the 1-liter aquarium in the same room. The fish were tested in the same chronological order in both tests. Fish were transferred to a novel tank (trapezoid 1.5-liter tank; Aquatic Habitats, Apopka, FL; size in cm: height $15.2 \times$ width $7.1 \times$ length 27.9 at the top and 22.5 at bottom) and filmed for six minutes from the side. We tested 12 fish per fraction and concentration. For space occupancy analysis, tanks were separated into two areas as previously described (Egan et al. 2009): a "top" area corresponding to one half of the volume and a "bottom" area corresponding to the other half. The dependent variables measured were time spent in each area (top, bottom; in s) per minute, total distance traveled $(\mathrm{cm})$ and time spent immobile (s).

\subsection{Data recording and analysis}

For swimming activity, maze exploration and novel tank experiments, videos were recorded with an analog ICD-48E camera (Ikegami) and a 2.7-13.5 mm lens (Fujinon), linked to a PC with an acquisition card and Ethovision XT software (Noldus, The Netherlands). In all experiments, EthoVision XT software was used for track extraction and analysis. Data were acquired by EthoVisionXT at a rate of 25 frames per second, and variables were nested for further analysis, every 30 minutes for the 24-h swimming tests on six-month-old fish and every minute during the photomotor response test (distance traveled in $\mathrm{cm}$ and time spent immobile; in s). In photomotor response tests, the distance traveled was also summed over 15-minute periods (Light on-1, Light-off, Light on-2). Nesting was carried out every five minutes (duration of the test) in maze experiments and every one or six minutes in novel tank experiments (distance traveled in $\mathrm{cm}$, time spent in top area in $\mathrm{s}$, and time spent immobile in 
s). For assessments of the time spent immobile, we used the mobility detection function of EthoVision XT, which has a lower threshold for separating immobility from mobility, and an upper threshold for separating mobility from highly mobile. The lower threshold was set at $20 \%$ for assessments of immobility, indicating that a change of no more than $20 \%$ in the pixels of a detected object between two consecutive samples would be considered to indicate immobility (see EthoVision XT Reference Manual).

\subsection{Statistical analysis}

Statistical analyses were carried out with Statistica 9.0 (Statsoft, Tulsa, OK, USA) software. Generalized linear models (GLM) were applied in each case, for statistical assessment of the effect of PAH concentration on measurements of locomotor activity, photomotor response, the tendency to explore and the anxiety level. For each fraction (PY, HO or LO), we tested concentration (control, 0.3X, 1X and 3X) and period (day vs. night in 24-h locomotion; Light on-1, Light-off, Light on-2 during the photomotor response test; min-1 to 6 in the novel tank test) or area (start, shallow and deep in the T-maze; start, close or distant in Z-maze; top in the novel tank test) as fixed factors. Fish and session were treated as random factors in this repeated measures analysis, to overcome the problem of pseudoreplication. Sex was also treated as a fixed factor in analyses of six-month-old fish. Body mass was tested as a covariable, but was never found to have a significant effect. We also analyzed the interaction between concentration and period. Throughout the results section, we report only significant fixed factor or interaction effects. Individual successes or failures to reach the deep area (Tmaze) or quadrant 16 (Z-maze) were compared between concentrations in chi $^{2}$ tests followed by two-tailed paired Fisher's exact tests (Control vs. each concentration). The proportion of the maze explored was subjected to arcsine transformation before GLM analysis. All statistical tests were carried out at the $5 \%$ significance level. Newman-Keuls post hoc tests were carried out in each case. The results are reported in the text and figures as means \pm SEM.

\section{Results}

This work is part of a larger program including analyses of the changes in several physiological variables following exposure to the diets described here. Chemical analyses of the fractions, diets and metabolites are presented elsewhere (Vignet et al. 2014b). Briefly, the PY fraction contained a high proportion of heavy PAHs and almost no methylated derivatives. The $\mathrm{HO}$ fraction contained moderate levels of heavy PAHs and methylated derivatives. The LO fraction contained low levels of heavy PAHs and a high level of alkylated derivatives. The concentrations of the 16 US-EPA PAHs in $1 \mathrm{X}$ diets were PY-1X: $4505 \pm 1527$, LO-1X: $2739 \pm 231$ and HO-1X: $1887 \pm 130 \mathrm{ng} \cdot \mathrm{g}^{-1} \mathrm{dw}$. The total concentration of PAHs (including methylated derivatives) measured in the $1 \mathrm{X}$ diets were: $5816 \pm 1433$, $4663 \pm 360$ and $6726 \pm 278 \mathrm{ng} \cdot \mathrm{g}^{-1} \mathrm{dw}$ for PY, HO and LO, respectively. The quantification of hydroxylated metabolites in $15 \mathrm{dpf}$ larvae confirmed that the fish had effectively been exposed, and the results obtained were consistent with diet composition (Vignet et al. 2014b).

\subsection{4-h locomotion in adults}

In six-month-old adults, we assessed 24-h locomotion and compared the distance traveled between the day and night periods (Fig. 1 a-c). No differences were observed between the day and night periods for PY and LO, whereas fish exposed to $\mathrm{HO}$ displayed significantly higher levels of activity during the day than during the night $(F=10.23, p<0.001)$. 
Concentration and sex had no significant effect and there was no significant interaction between fixed factors. During both day and night periods, the fish remained immobile for about $50-60 \%$ of the total time (Fig. $1 \mathrm{~d}-\mathrm{f}$ ). For fish on PY diets, the time spent immobile was greater during the day than during the night $(F=44.84 ; p<0.001)$, but neither concentration nor sex had any significant effect on this variable and no significant interactions were detected. A similar pattern, with longer periods of immobility during the day than during the night, was observed for fish on $\mathrm{HO}$ diets $(F=46.43 ; p<0.001)$ but, in this case, a difference was also observed between concentrations $(F=13.24 ; p<0.001)$ and there was a significant interaction between period and concentration $(F=3.09 ; p<0.01)$. Indeed, fish on $\mathrm{HO}$ diets spent less time immobile during the day than control fish, for $\mathrm{HO}-1 \mathrm{X}$ and $\mathrm{HO}-3 \mathrm{X}(p<0.05$ and $p<0.001$ respectively), whereas fish on the HO-3X diet spent less time immobile than the control fish during the night $(p<0.001)$. Sex had no effect. Fish on LO diets were less immobile during the day than control fish $(F=119.63 ; p<0.001)$ and significant differences were observed between concentrations $(F=5.25 ; p<0.01)$, but there was no interaction and no effect of sex. In this case, all fish fed LO diets spent a significantly shorter time immobile during the day than the control fish.

\subsection{Photomotor response in juveniles and adults}

GLM analyses revealed significant differences in the photomotor response between periods, for two-month-old PY fish ( $F=16.95 ; p<0.001$; Fig. $2 a$ ) with higher levels of activity during and after the dark challenge. There was a trend for PY-3X juveniles to display a smaller increase in activity during the dark period, but there was no significant difference between concentrations, whatever the period (Fig. 2a, focus graph). In six-month-old fish, similar significant differences between periods $(F=42.33 ; p<0.001)$ were observed, but with no effect of concentration or sex (data not shown).

Two-month old fish spent more time immobile before the challenge than after the challenge (Fig. 2b; period effect $F=64.63, p<0.001)$. A concentration effect $(F=3.36, p<0.05)$ was observed (PY-1X fish spent more time immobile during Light on-1, $p<0.05$ ) but no significant interaction was detected. For six-month-old fish, we observed only a similar period effect $(F=214.82, p<0.001$, data not shown).

In two-month-old fish exposed to the $\mathrm{HO}$ fraction, there were significant differences between periods ( $F=7.26$; $p<0.001$; Fig. 2c), with greater locomotion during and after the challenge, but no significant concentration effect or interaction was detected. Similar results were obtained for six-month-old fish (data not shown), with significant differences between periods $(F=55.94 ; p<0.001)$ and between concentrations $(F=3.73 ; p<0.05)$, and there was a significant interaction between period and concentration $(F=2.23 ; p<0.05)$, with $\mathrm{H} 0-3 \mathrm{X}$ fish displaying lower levels of locomotor activity during the dark period $(p<0.001)$ and the following Light on2 period $(p<0.05)$.

A period effect on the time spent immobile was observed in two-month-old fish (Fig. 2d; $F=6.40, p<0.01$ ), with a small decrease during and after the challenge. There was no concentration effect but a significant interaction between period and concentration was detected $(F=3.14, p<0.001)$ : HO-3X fish spent more time immobile during the period in which the light was switched off $(p<0.05)$. For six-month-old fish, a period effect was observed, with the same pattern as for two-month-old fish ( $F=104.04, p<0.001$, data not shown), together with a concentration effect $(F=7.36, p<0.001)$ and a significant interaction $(p<0.001)$ : HO-3X fish spent less time immobile than control fish during the Light on-1 and Light on-2 periods $(p<0.01)$. A sex effect $(F=6.85, p<0.01)$ was also detected, with males spending less time immobile $(262.51 \pm 28.88 \mathrm{~s})$ than females $(322.44 \pm 35.19 \mathrm{~s})$. No other significant interaction was detected. 
The locomotor activity of two-month-old LO-3X fish was lower than that of fish fed other concentrations of LO (concentration effect, $F=12.68$; $p<0.001$ ) throughout the photomotor response challenge, with no difference in the distance traveled whatever the light period for LO-3X (Fig. 2e). A period effect was seen for other fish $(F=3.42 ; p<0.05)$, but there was no significant interaction. Similar responses were observed for six-month-old LO-3X fish, with lower levels of activity (data not shown) and a significant difference between periods $(F=31.54 ; p<0.001)$, together with a sex effect $(F=6.19, p<0.05)$ : female fish were less active $(1611 \pm 98.58 \mathrm{~cm} / 15 \mathrm{~min})$ than male fish $(1843 \pm 106.95 \mathrm{~cm} / 15 \mathrm{~min})$ with no other significant interactions detected.

Two-month-old fish (Fig. 2f) spent more time immobile before the challenge (period effect $F=18.10, p<0.001$ ) but there was no concentration effect and no significant interaction. Sixmonth-old fish also spent more time immobile before the challenge (period effect $F=67.85$, $p<0.001$, data not shown) and there was a concentration effect for fish of this age $(F=4.70$, $p<0.01)$ : LO-1X and LO-3X fish spent less time immobile during Light on-2 $(p<0.001$ and $p<0.05$ respectively), but no significant interaction was detected. A sex effect was found $(F=15.54, p<0.001)$ with males spending less time immobile $(217.51 \pm 23.85 \mathrm{~s})$ than females $(276.21 \pm 26.09 \mathrm{~s})$. No other significant interactions were observed.

\subsection{Exploration of a novel environment}

We investigated the exploration of the T-maze (PY diets) and the Z-maze (HO and LO diets) in two- and six-month-old fish (data not shown for the six-month-old fish).

For all three diets, there was a trend towards a dose-dependent increase in the time taken to leave the start area, but a significant difference between concentrations was observed only for fish fed $\mathrm{HO}$ diets $(F=5.27 ; p<0.01)$ with fish on the HO-3X diet taking almost twice as long to exit the start area for the first time as the other fish fed $\mathrm{HO}(p<0.01$; Fig. 3). A significant sex effect was observed for LO fish $(F=7.73, p<0.01)$, with males leaving the start area earlier $(36.12 \pm 38.34 \mathrm{~s})$ than females $(58.42 \pm 40.23 \mathrm{~s})$. No other significant interactions were measured.

In the T-maze challenge, whatever the concentration, two-month-old fish spent more time in the shallow area than in the other two areas $(F=21.36 ; p<0.001 ;$ Fig. 4a). No other interactions were measured. Similar results were obtained for six-month-old fish $(F=10.20$, $p<0.001$; data not shown).

For fish on the $\mathrm{HO}$ diet, differences were observed in the time spent in the various areas $(F=14.70 ; p<0.001$; Fig. $4 b)$ and there was a significant interaction between area and concentration ( $F=2.83 ; p=0.013)$ : a dose-dependent decrease in the time spent in the distant area was observed, with $\mathrm{HO}-3 \mathrm{X}$ fish spending only a quarter the time spent by control fish in this area $(p<0.05)$. A significant difference in the time spent in the various areas was observed in six-month old fish ( $F=8.13 ; p<0.001$; HO-3X fish not tested) and post hoc tests revealed that this difference was due to less time being spent in the start area. There was no effect of sex and no other interaction.

Two-month-old fish on LO diets spent more time in the close area than control fish $(F=10.65$; $p<0.001$; Fig. 4c) but no difference between concentrations and no interactions were observed. No differences were observed with six-month-old adults.

We evaluated the exploratory tendencies of the tested fish further, by analyzing individual success or failure to reach the deep zone (T-maze) or quadrant 16 (the farthest away from the start area in the Z-maze; Fig. 5a). For two-month-old fish on PY diets, success in reaching the deep zone depended on concentration $\left(\mathrm{chi}^{2}=8.0, p<0.05\right)$, with $0.3 \mathrm{X}$ and $3 \mathrm{X}$ 
diets giving similar results to those obtained for control fish and lower scores obtained for the $1 \mathrm{X}$ diet (only half the fish reached the deep area). The success of $\mathrm{HO}$ fish in reaching the farthest area of the maze also depended on concentration $\left(\mathrm{chi}^{2}=16.6, p<0.001\right)$ : higher success rates were obtained for control and $0.3 \mathrm{X}$ fish than for $1 \mathrm{X}$ and $3 \mathrm{X}$ fish. Success rates were similar for all fish fed LO diets (6 to 9), regardless of concentration.

For each fraction, we focused our analyses on fish reaching the deep zone or quadrant 16. Whatever the fraction, the time taken by two-month-old fish to reach the deep zone or quadrant 16 was not affected by the exposure, although fish fed PY or $\mathrm{HO}$ fish tended to take longer to reach these zones than control fish (Fig. 5b). In six-month-old fish, a significant concentration effect was shown only for $\mathrm{HO}(F=3.75, p<0.05)$ : control fish took significantly less time to reach quadrant 16 than fish fed the $0.3 \mathrm{X}$ and $1 \mathrm{X}$ diets. A sex effect was observed for LO fish $(F=10.95, p<0.01)$, with males taking half the time to reach quadrant 16 $(77.46 \pm 14.60 \mathrm{~s})$ than females $(150.55 \pm 17.71 \mathrm{~s})$. No other interactions were observed.

For the Z-maze, the tendency to explore, analyzed by determining the most distant quadrant reached, decreased significantly with increasing dose in $\mathrm{HO}$ fish $(F=4.50 ; p<0.01$, Fig. $5 c)$, with $\mathrm{HO}-1 \mathrm{X}$ fish reaching a significantly lower-numbered quadrant than $0.3 \mathrm{X}$ fish $(p<0.05)$, with a further halving of the quadrant number reached for HO-3X fish $(p<0.001)$. A similar tendency for a decrease in exploratory tendency with increasing dose was observed in sixmonth-old fish ( $F=5.17 ; p<0.05$; data not shown). No significant effect was detected for LO fish.

\subsection{Novel tank test}

In all cases, regardless of the fraction and concentration considered, the proportion of time spent in the top area increased with time during the six-minute challenge $(p<0.001 ;$ Fig. 6$)$. In two-month-old fish fed PY, the time spent in the top area increased significantly over time $(F=19.49, p<0.001)$ and concentration effects were observed $(F=5.15 ; p<0.001$; Fig. 6a), with PY-3X fish spending less time in the top area than control fish $(p<0.05)$, but no interactions were observed. The distance traveled and the time spent immobile were similar for all concentrations (Fig. 6b-c). In six-month-old fish, the same increase in the time spent in the top area over time was observed $(F=19.50 ; p<0.001)$, together with similar differences between concentrations $(F=3.14 ; p<0.05)$, with six-month-old PY-1X fish spending less time than control fish in the top area $(p<0.05)$. No sex effects or other interactions were detected.

In two-month-old $\mathrm{HO}$ fish, significant differences over time $(F=10.21 ; p<0.001)$ and between concentrations $(F=21.93, p<0.001)$ were observed during the six-minute challenge, with $\mathrm{HO}$ $1 \mathrm{X}$ and HO-3X fish spending less time in the top area than control fish $(p<0.001$, for both concentrations). For six-month-old $\mathrm{HO}$ fish, only time was a significant factor $(F=3.90$; $p<0.01)$, with fish showing the same pattern as two-month-old fish. The distance traveled was also significantly lower for two-month-old HO-3X fish than for fish on other $\mathrm{HO}$ diets $(F=7.41 ; p<0.001)$, and these fish tended to spend longer periods of time immobile $(p=0.078)$. In tests on six-month-old fish, significant differences were observed only for the time spent in the top area at different times $(F=3.90 ; p<0.01)$, with fish displaying the same pattern as two-month-old fish. No effect of sex and no interactions were detected.

In two-month-old LO fish, we observed an effect of time $(F=7.44, p<0.001)$ and of concentration $(F=2.88 ; p<0.05)$, with LO-3X fish spending less time in the top area than control fish. LO-3X also traveled shorter distances than control fish $(F=4.44, p<0.01$; posthoc $p<0.01$ ) and there was no significant difference in time spent immobile between concentrations. In six-month-old fish, we detected effects of time $(F=12.32, p<0.001)$ and concentration on the time spent in the top area $(F=2.64 ; p<0.05)$ : contaminated fish spent less time in the top area than control fish. There was also a sex effect $(F=6.35, p<0.05)$, with 
males spending more time in the top area $(22.71 \pm 17.64 \mathrm{~s})$ than females $(18.79 \pm 16.15 \mathrm{~s})$. No other significant interactions were detected.

\section{Discussion}

In this study, we exposed fish to three PAH mixtures through diet, beginning at the first meal (5 dpf), and continuously thereafter (Vignet et al. 2014b). This exposure route was chosen because it is a major contamination pathway for fish in natural conditions (Johnson et al. 2007, Varanasi et al. 1993, Yanagida et al. 2012). The three mixtures used were extracted aromatic fractions with different compositions, representatives of different mixtures encountered in the environment. PY was characterized by a high proportion of heavy PAHs and a very low proportion of alkylated PAHs. LO contained a high proportion of alkylated $\mathrm{PAHs}$ and a low proportion of heavy $\mathrm{PAHs}$, whereas $\mathrm{HO}$ had intermediate proportions of both groups of PAHs. The total concentration of PAHs was in the 4.6-6.7 $\mu \mathrm{g} . \mathrm{g}^{-1} \mathrm{dw}$ range for the intermediate $1 \mathrm{X}$ concentration. This concentration was close to the targeted concentration of $5 \mu \mathrm{g} \cdot \mathrm{g}^{-1} \mathrm{dw}$, reported in copepods and bivalves in chronically contaminated areas (Cailleaud et al. 2007, Jeanneret et al. 2002, Le Goff et al. 2006, Payne et al. 2008), but lower than concentrations occasionally found after accidental pollution incidents, such as the $14.4 \mu \mathrm{g} \cdot \mathrm{g}^{-1}$ measured in mussels after the Exxon Valdez oil spill (Payne et al. 2008). The levels of exposure used in this study were, therefore, representative of different situations occurring in the environment. Heavy metals and other organic pollutants (e.g. PCBs) have been shown to modify behavior. Aromatic fractions were prepared with methods excluding the copurification of heavy metals. PCBs are copurified with PAHs, but there are no PCBs in petrogenic fractions. For the PY fraction extracted from Oissel sediment, previous reports have indicated the presence of PCBs at very low concentrations ( $\sum$ PCBs $=70 \mathrm{ng}^{-1} \mathrm{~g}^{-1}$ and dioxin-like congener $\mathrm{CB} 118=8.4 \mathrm{ng} \cdot \mathrm{g}^{-1}$ (Cachot et al. 2006)). We therefore conclude that the behavioral defects reported here are essentially due to the PAHs present in the different fractions.

Our results for the set of variables studied here indicate that all three fractions caused behavioral disruptions. The pattern of disruption was similar, but there were clear differences between fractions in terms of the severity of the disruptions observed. The HO fraction was the most deleterious, followed by the LO and PY fractions. These results suggest that alkylated PAHs play an important role in triggering behavioral disruption, as the LO fraction (mostly alkylated PAHs) was more toxic than the PY fraction (heavy PAHs). The higher toxicity of the $\mathrm{HO}$ fraction than of the other two fractions suggests a possible additive effect of heavy and alkylated PAHs.

Major advances have been made in the identification and characterization of behavioral disruptions in zebrafish larva, juveniles and adults, in terms of basic traits, such as stress or anxiety levels, and more complex traits, such as social interactions and learning abilities (Arthur \& Levin 2001, Bailey et al. 2013, Cachat et al. 2010a, Champagne et al. 2010, Egan et al. 2009, Norton \& Bally-Cuif 2010, Steenbergen et al. 2011, Stewart et al. 2012). Tests and variables for evaluating the disruption of these traits have also been defined. These tests have also been used to evaluate the effects of exposure to environmental pollutants on fish behavioral responses per se or as an integrated indicator of physiopathological disruptions (Baraban et al. 2005, He et al. 2011, Kusch et al. 2008, Levin et al. 2003, Levin et al. 2011, Nakayama et al. 2005, Pean et al. 2013, Saili et al. 2012, Schmidt et al. 2005, Timme-Laragy et al. 2006).

There have been few studies of the consequences of PAH exposure for fish behavior. Most of the studies published to date were performed after brief waterborne exposure to a single $\mathrm{PAH}$ or a simple mixture of individual PAHs. In these studies, the variables monitored were 
swimming ability (Almeida et al. 2012, Gravato \& Guilhermino 2009, Oliveira et al. 2012) or behavioral traits evaluated in groups (Correia et al. 2007, Goncalves et al. 2008). Exposure to single compounds has been shown to lead to a decrease in swimming ability, evaluated in a device similar to a swim-tunnel, and the variables considered in these studies were resistance to a counter current flow and/or swimming velocity (Almeida et al. 2012, Gravato \& Guilhermino 2009, Oliveira et al. 2012). These effects are of the utmost importance in an ecological context, because the disruption of swimming ability may greatly impair the ability of the fish to find and capture preys or to avoid predators. However, these effects may have a number of causes not related to behavior per se; such as an impaired energy budget or respiration. In the studies focusing on behavioral traits, both swimming ability and social interactions were monitored (Correia et al. 2007, Goncalves et al. 2008). In these cases, monitoring was performed on groups of fish and the authors concluded that locomotor activity decreased after exposure to fluorene, pyrene or phenanthrene, or to a mixture of these three PAHs and that social interactions decreased after exposure to phenanthrene (Correia et al. 2007, Goncalves et al. 2008). In these group studies, it is difficult to identify the behavioral disruptions affecting individual fish, due to potential interactions between fish reflecting group structure or hierarchy. Nevertheless, all these articles concluded that exposure led to a decrease in swimming activity, which was presented as a lethargymediated effect of the tested PAHs.

The protocols used here monitored individual behavior, and were chosen for the evaluation of several behavioral traits: circadian spontaneous swimming activity, response to a light challenge, exploration ability and behavioral response to a novel environment. The tests used and the variables extracted could also be used for the evaluation of integrative traits, such as anxiety level. Hence, our results can be analyzed in terms of two groups of broad effects. Firstly, control fish spent more than half the time [57-72\%] immobile, during both the day and night periods, whereas the proportion of time spent immobile was significantly lower for $\mathrm{HO}-3 \mathrm{X}$ fish ( $20 \%$ of the time, during both periods) and for HO-1X and LO-0.3X, LO-1X and LO-3X fish during the day period ( $<40 \%$ of the time). Thus, the contaminated fish had shorter resting times and therefore, probably, a greater demand for energy. They also traveled a similar distance to control fish, suggesting a more continuous low swimming speed. Alternatively, these fish may have been displaying bouts of high activity due to "erratic" movements, indicative of anxiety (Cachat et al. 2010b, Egan et al. 2009).

This second interpretation would be consistent with the second group of effects observed. Behavioral responses in mazes or the novel tank were characterized by a delay in exit from the refuge zone, lower levels of exploration (in mazes; $\mathrm{HO}-1 \mathrm{X}$ and $\mathrm{HO}-3 \mathrm{X}$ ) and less time spent in the top area (in the novel tank; PY-3X, HO-1X, HO-3X and LO-3X). All these findings indicate an increase in anxiety (Cachat et al. 2010b, Egan et al. 2009, Stewart et al. 2010, Stewart et al. 2011). High cortisol concentrations are often considered an indicator of anxiety/stress (Alsop \& Vijayan 2008, Cachat et al. 2010b). An increase in cortisol concentration has been observed in trout after exposure to $\mathrm{BaP}$ and a prototypic $\mathrm{AhR}$ agonist, $\beta$-naphthoflavone (Gesto et al. 2008, Tintos et al. 2008), and in three-spined stickleback after exposure to produced water (Knag \& Taugbol 2013). These findings are consistent with exposure to PAHs triggering anxiety. Further studies, with the inclusion of anxiolytic and anxiogenic drugs with the different fractions and concentrations, together with cortisol determinations in the water, would be useful for testing this hypothesis (Felix et al. 2013).

In addition to these principal findings, we also found that some responses were weaker in adult fish than in juveniles, suggesting that the sensitivity of these tests is greater in juveniles, which should be preferred for such studies. Sex effects were also occasionally observed; suggesting that the sex of the fish tested should also be taken into account whenever possible. 
A strong induction of tumorigenesis has been reported in fish exposed to all three fractions tested here (Larcher et al. In revision), and some of the behavioral disruptions identified here could be a consequence of this. However, no tumors were found in the nervous system of the fish, ruling out a direct effect of tumors on behavior. It remains possible that a global failure of metabolism due to tumor development hinders the expression of some types of behavior. However, respiratory metabolism was evaluated for both PY- and HO-exposed fish and no effect of exposure was detected (Julie Lucas, personal communication). This suggests that no such mechanism is involved in the onset of behavioral disruptions described here.

In the framework of this project, we obtained several lines of evidence for endocrine disruption, such as a shift in the timing of hormone expression or spawning disruption (unpublished results). Steroid hormones regulate reproductive and non-reproductive behavior and, as a consequence, endocrine disruption modifies individual or social behavior in fish (Belanger et al. 2010, Filby et al. 2012, Oliveira et al. 2009, Saaristo et al. 2010, Salierno \& Kane 2009, Soffker et al. 2012, Stacey 2003) and other species (Ottinger et al. 2013, Panzica et al. 2007). It is therefore tempting to suggest that the endocrine disruption activity of the fractions tested contributed to the behavioral modifications described here.

However, the mechanisms underlying these behavioral disruptions remain largely unknown. Monoamines, including serotonin and dopamine, are involved in the control of a wide number of biological processes (see reviews (Hoglund et al. 2005, Øverli et al. 2005)). BaP and $\beta$ naphthoflavone disrupt dopaminergic and serotonergic systems in the brain of rainbow trout, as revealed by an increase in the turnover of these neurotransmitters (Gesto et al. 2008, Gesto et al. 2009). In addition, as experimental exposure began early in this study (5 dpf), at a time at which neurogenesis was still underway and the nervous system was maturing (Kastenhuber et al. 2010, McGraw et al. 2012, Souza \& Tropepe 2011), the phenotypes observed may reflect this early disruption. Similar effects have been demonstrated following the embryonic disruption of monoamine systems (Dennis et al. 2013, Shabanov et al. 2005, Silva et al. 2013) or early exposure to silver or cadmium (Kusch et al. 2008, Powers et al. 2011). Such a delayed effect has also been demonstrated in zebrafish, following the exposure of embryos or larvae to PAH mixtures (Vignet et al. 2014a), in rat, after perinatal exposure (Crépeaux et al. 2012) and after the exposure of Pacific herring embryos to weathered crude oil(Carls et al. 1999).

These results establish parallels between the effects of chronic exposure in fish and the neurobehavioral disruptions observed in humans and rodents after exposure to PAHs (Bouayed et al. 2009, Crépeaux et al. 2012, 2013, Edwards et al. 2010, Jedrychowski et al. 2003, Perera et al. 2012, Saunders et al. 2001, 2003, Tang et al. 2008, Xia et al. 2011). In addition to confirming findings for humans, studies of this kind provide an opportunity to decipher the underlying mechanisms. Finally, this study provides support for the use of behavioral endpoints in the framework of environmental quality assessment.

In conclusion, behavioral disruptions have been observed in zebrafish, after chronic, longterm dietary exposure to PAHs. These disruptions, indicative of an increase of anxiety, may have detrimental consequences in terms of the performance of the exposed fish, their ability to survive and to explore their environment and, hence, their ability to contribute to next generation. Furthermore, the severity of the disruption depended on the mixture used, with the $\mathrm{HO}$ and LO fractions having a more severe effect than PY. More behavioral analyses, associated with molecular research, are required to identify the mechanisms underlying the observed disruption and the particular toxicity of alkylated PAHs. 


\section{Acknowledgements}

We thank Manon Goubeau for helping to carry out the experiments. This study received funding from the ANR project ConPhyPoP (CES 09_002) and CPER A2E. This second project is jointly funded by the European Union and the European Fund for Regional Development. A PhD grant was provided by the Région Poitou-Charentes and I'Institut Français de Recherche pour l'Exploitation de la Mer (C.V.). This work was part of the LABEX COTE cluster of excellence "Continental to coastal ecosystems".

\section{References}

Ali S, Champagne DL, Alia A, Richardson MK (2011a): Large-scale analysis of acute ethanol exposure in zebrafish development: a critical time window and resilience. PLoS One 6, e20037

Ali S, Champagne DL, Spaink HP, Richardson MK (2011b): Zebrafish embryos and larvae: a new generation of disease models and drug screens. Birth Defects Res C Embryo Today 93, 115-33

Almeida JR, Gravato C, Guilhermino L (2012): Challenges in assessing the toxic effects of polycyclic aromatic hydrocarbons to marine organisms: a case study on the acute toxicity of pyrene to the European seabass (Dicentrarchus labrax L.). Chemosphere 86, 926-937

Alsop D, Vijayan MM (2008): Development of the corticosteroid stress axis and receptor expression in zebrafish. Am J Physiol Regul Integr Comp Physiol 294, R711-9

Arthur D, Levin E (2001): Spatial and non-spatial visual discrimination learning in zebrafish (Danio rerio). Animal Cognition 4, 125-131

Bailey J, Oliveri A, Levin ED (2013): Zebrafish model systems for developmental neurobehavioral toxicology. Birth Defects Research Part C: Embryo Today: Reviews 99, 14-23

Baraban SC, Taylor MR, Castro PA, Baier H (2005): Pentylenetetrazole induced changes in zebrafish behavior, neural activity and c-fos expression. Neuroscience 131, 759-768

Baumard P, Budzinski H, Garrigues P, Sorbe JC, Burgeot T, Bellocq J (1998): Concentrations of PAHs (polycyclic aromatic hydrocarbons) in various marine organisms in relation to those in sediments and to trophic level. Marine Pollution Bulletin 36, 951-960

Belanger RM, Pachkowski MD, Stacey NE (2010): Methyltestosterone-induced changes in electro-olfactogram responses and courtship behaviors of cyprinids. Chemical senses $35,65-74$

Benlahcen KT, Chaoui A, Budzinski H, Bellocq J, Garrigues P (1997): Distribution and sources of polycyclic aromatic hydrocarbons in some Mediterranean coastal sediments. Marine Pollution Bulletin 34, 298-305

Bouayed J, Desor F, Soulimani R (2009): Subacute oral exposure to benzo[alpha]pyrene (B[alpha]P) increases aggressiveness and affects consummatory aspects of sexual behaviour in male mice. J Hazard Mater 169, 581-5

Budzinski H, Jones I, Bellocq J, Piérard C, Garrigues P (1997): Evaluation of sediment contamination by polycyclic aromatic hydrocarbons in the Gironde estuary. Marine Chemistry 58, 85-97

Cachat J et al. (2010a): Modeling withdrawal syndrome in zebrafish. Behav Brain Res 208, $371-6$

Cachat $\mathrm{J}$ et al. (2010b): Measuring behavioral and endocrine responses to novelty stress in adult zebrafish. Nat Protoc 5, 1786-99

Cachot J, Geffard O, Augagneur S, Lacroix S, Le Menach K, Peluhet L, Couteau J, Denier X, Devier MH, Pottier D, Budzinski H (2006): Evidence of genotoxicity related to high 
PAH content of sediments in the upper part of the Seine estuary (Normandy, France). Aquatic Toxicology 79, 257-267

Cailleaud K, Forget-Leray J, Souissi S, Hilde D, LeMenach K, Budzinski H (2007): Seasonal variations of hydrophobic organic contaminant concentrations in the water-column of the Seine Estuary and their transfer to a planktonic species Eurytemora affinis (Calanoida, copepoda). Part 1: PCBs and PAHs. Chemosphere 70, 270-280

Carls MG, Rice SD, Hose JE (1999): Sensitivity of fish embryos to weathered crude oil: Part I. Low-level exposure during incubation causes malformations, genetic damage, and mortality in larval pacific herring (Clupea pallasi). Environmental Toxicology and Chemistry 18, 481-493

Champagne DL, Hoefnagels CC, de Kloet RE, Richardson MK (2010): Translating rodent behavioral repertoire to zebrafish (Danio rerio): relevance for stress research. Behav Brain Res 214, 332-42

Chapman BB, Morrell LJ, Krause J (2010): Unpredictability in food supply during early life influences boldness in fish. Behavioral Ecology 21, 501-506

Correia AD, Gonçalves R, Scholze M, Ferreira M, Henriques MA-R (2007): Biochemical and behavioral responses in gilthead seabream (Sparus aurata) to phenanthrene. Journal of Experimental Marine Biology and Ecology 347, 109-122

Crépeaux G, Bouillaud-Kremarik P, Sikhayeva N, Rychen G, Soulimani R, Schroeder H (2012): Late effects of a perinatal exposure to a 16 PAH mixture: Increase of anxietyrelated behaviours and decrease of regional brain metabolism in adult male rats. Toxicology Letters 211, 105-113

Crépeaux G, Bouillaud-Kremarik P, Sikhayeva N, Rychen G, Soulimani R, Schroeder H (2013): Exclusive prenatal exposure to a $16 \mathrm{PAH}$ mixture does not impact anxietyrelated behaviours and regional brain metabolism in adult male rats: $\mathrm{A}$ role for the period of exposure in the modulation of PAH neurotoxicity. Toxicology Letters 221, $40-46$

Creton R (2009): Automated analysis of behavior in zebrafish larvae. Behavioural Brain Research 203, 127-136

Dennis RL, Fahey AG, Cheng HW (2013): Alterations to embryonic serotonin change aggression and fearfulness. Aggressive behavior 39, 91-98

Edwards SC, Jedrychowski W, Butscher M, Camann D, Kieltyka A, Mroz E, Flak E, Li Z, Wang S, Rauh V, Perera F (2010): Prenatal exposure to airborne polycyclic aromatic hydrocarbons and children's intelligence at 5 years of age in a prospective cohort study in Poland. Environ Health Perspect 118, 1326-31

Egan RJ, Bergner CL, Hart PC, Cachat JM, Canavello PR, Elegante MF, Elkhayat SI, Bartels BK, Tien AK, Tien DH, Mohnot S, Beeson E, Glasgow E, Amri H, Zukowska Z, Kalueff AV (2009): Understanding behavioral and physiological phenotypes of stress and anxiety in zebrafish. Behav Brain Res 205, 38-44

Eisler R (1987): Polycylic Aromatic Hydrocarbons Hazards to Fish, Wildlife, and Invertebrates: A Synoptic Review. U.S. Fish and Wildlife Service, Washington, DC. Biological Report 85, 1-11

Felix AS, Faustino Al, Cabral EM, Oliveira RF (2013): Noninvasive measurement of steroid hormones in zebrafish holding-water. Zebrafish 10, 110-5

Filby AL, Paull GC, Searle F, Ortiz-Zarragoitia M, Tyler CR (2012): Environmental estrogeninduced alterations of male aggression and dominance hierarchies in fish: a mechanistic analysis. Environ Sci Technol 46, 3472-9

Gerlai R, Lahav M, Guo S, Rosenthal A (2000): Drinks like a fish: zebra fish (Danio rerio) as a behavior genetic model to study alcohol effects. Pharmacology Biochemistry and Behavior 67, 773-782

Gesto M, Soengas JL, Miguez JM (2008): Acute and prolonged stress responses of brain monoaminergic activity and plasma cortisol levels in rainbow trout are modified by PAHs (naphthalene, beta-naphthoflavone and benzo(a)pyrene) treatment. Aquatic Toxicology 86, 341-351 
Gesto M, Tintos A, Soengas JL, Miguez JM (2009): beta-Naphthoflavone and benzo(a)pyrene alter dopaminergic, noradrenergic, and serotonergic systems in brain and pituitary of rainbow trout (Oncorhynchus mykiss). Ecotoxicology and Environmental Safety 72, 191-198

Goncalves R, Scholze M, Ferreira AM, Martins M, Correia AD (2008): The joint effect of polycyclic aromatic hydrocarbons on fish behavior. Environmental Research 108, 205-213

Gravato C, Guilhermino L (2009): Effects of Benzo(a)pyrene on Seabass (Dicentrarchus labrax L.): Biomarkers, Growth and Behavior. Human and Ecological Risk Assessment: An International Journal 15, 121-137

He J, Yang D, Wang C, Liu W, Liao J, Xu T, Bai C, Chen J, Lin K, Huang C, Dong Q (2011): Chronic zebrafish low dose decabrominated diphenyl ether (BDE-209) exposure affected parental gonad development and locomotion in F1 offspring. Ecotoxicology 20, 1813-22

Hinton DE, Kullman SW, Hardman RC, Volz DC, Chen P-J, Carney M, Bencic DC (2005): Resolving mechanisms of toxicity while pursuing ecotoxicological relevance? Marine Pollution Bulletin 51, 635-648

Hoglund E, Weltzien FA, Schjolden J, Winberg S, Ursin H, Doving KB (2005): Avoidance behavior and brain monoamines in fish. Brain Research 1032, 104-110

Jeanneret H, Chantereau S, Belliaeff B, Ratiskol G, Allenou J-P, Piclet G (2002): Suivi sanitaire et environnemental des conséquences de la marée noire de l'Erika. In: Cedre (Hrsg.), Colloque SAFERSEAS: les leçons techniques de l'Erika et des autres accidents, Brest

Jedrychowski W, Whyatt RM, Camann DE, Bawle UV, Peki K, Spengler JD, Dumyahn TS, Penar A, Perera FF (2003): Effect of prenatal PAH exposure on birth outcomes and neurocognitive development in a cohort of newborns in Poland. Study design and preliminary ambient data. Int J Occup Med Environ Health 16, 21-9

Johnson LL, Ylitalo GM, Arkoosh MR, Kagley AN, Stafford C, Bolton JL, Buzitis J, Anulacion BF, Collier TK (2007): Contaminant exposure in outmigrant juvenile salmon from Pacific Northwest estuaries of the United States. Environmental Monitoring and Assessment 124, 167-194

Kastenhuber E, Kratochwil CF, Ryu S, Schweitzer J, Driever W (2010): Genetic dissection of dopaminergic and noradrenergic contributions to catecholaminergic tracts in early larval zebrafish. J Comp Neurol 518, 439-58

Knag AC, Taugbol A (2013): Acute exposure to offshore produced water has an effect on stress- and secondary stress responses in three-spined stickleback Gasterosteus aculeatus. Comp Biochem Physiol C Toxicol Pharmacol 158, 173-80

Kusch RC, Krone PH, Chivers DP (2008): Chronic exposure to low concentrations of waterborne cadmium during embryonic and larval development results in the longterm hindrance of antipredator behavior in zebrafish. Environ Toxicol Chem 27, 70510

Larcher T, Perrichon P, Vignet C, Ledevin M, Le Menach K, Lyphout L, Landi L, Clerandeau C, Lebihanic F, Ménard D, Burgeot T, Budzinski H, Akcha F, Cachot J, Cousin X (In revision): Carcinogenic but no genotoxic effects detected following chronic trophic exposure of zebrafish to 3 fractions of Polycyclic Aromatic Hydrocarbons (PAHs).

Latimer JS, Zheng J (2003): The Sources, Transport, and Fate of PAHs in the Marine Environment, PAHs: An Ecotoxicological Perspective. John Wiley \& Sons, Ltd, pp. 733

Lawrence C (2007): The husbandry of zebrafish (Danio rerio): A review. Aquaculture 269, 120

Le Goff J, Gallois J, Pelhuet L, Devier MH, Budzinski H, Pottier D, André V, Cachot J (2006): DNA adduct measurements in zebra mussels, Dreissena polymorpha, Pallas: Potential use for genotoxicant biomonitoring of fresh water ecosystems. Aquatic Toxicology $79,55-64$ 
Levin ED, Chrysanthis E, Yacisin K, Linney E (2003): Chlorpyrifos exposure of developing zebrafish: effects on survival and long-term effects on response latency and spatial discrimination. Neurotoxicol Teratol 25, 51-7

Levin ED, Sledge D, Roach S, Petro A, Donerly S, Linney E (2011): Persistent behavioral impairment caused by embryonic methylphenidate exposure in zebrafish. Neurotoxicology and Teratology 33, 668-673

MacPhail RC, Brooks J, Hunter DL, Padnos B, Irons TD, Padilla S (2009): Locomotion in larval zebrafish: Influence of time of day, lighting and ethanol. NeuroToxicology 30 , 52-58

Maximino C, de Brito TM, da Silva Batista AW, Herculano AM, Morato S, Gouveia A, Jr. (2010): Measuring anxiety in zebrafish: a critical review. Behav Brain Res 214, 15771

McGraw HF, Snelson CD, Prendergast A, Suli A, Raible DW (2012): Postembryonic neuronal addition in zebrafish dorsal root ganglia is regulated by Notch signaling. Neural development 7, 23

Nakayama K, Oshima Y, Hiramatsu K, Shimasaki Y, Honjo T (2005): Effects of Polychlorinated Biphenyls on the schooling behavior of japanese medaka (Oryzias latipes). Environmental Toxicology and Chemistry 24, 2588-2593

Neff JM (1979): Polycyclic aromatic hydrocarbons in the aquatic environment sources, fates, and biological effects. Applied Science Publishers, London

Ninkovic J, Bally-Cuif L (2006): The zebrafish as a model system for assessing the reinforcing properties of drugs of abuse. Methods 39, 262-274

Norton W, Bally-Cuif L (2010): Adult zebrafish as a model organism for behavioural genetics. BMC Neuroscience 11, 90

Oliveira M, Gravato C, Guilhermino L (2012): Acute toxic effects of pyrene on Pomatoschistus microps (Teleostei, Gobiidae): Mortality, biomarkers and swimming performance. Ecological Indicators 19, 206-214

Oliveira RF, Silva A, Canario AV (2009): Why do winners keep winning? Androgen mediation of winner but not loser effects in cichlid fish. Proceedings. Biological sciences / The Royal Society 276, 2249-56

Ottinger MA, Carro T, Bohannon M, Baltos Lf, Marcell AM, McKernan M, Dean KM, Lavoie E, Abdelnabi M (2013): Assessing effects of environmental chemicals on neuroendocrine systems: potential mechanisms and functional outcomes. Gen Comp Endocrinol 190, 194-202

Overli O, Winberg S, Pottinger TG (2005): Behavioral and Neuroendocrine Correlates of Selection for Stress Responsiveness in Rainbow Trout--a Review. Integrative and comparative biology 45, 463-74

Panzica GC, Viglietti-Panzica C, Mura E, Quinn MJ, Jr., Lavoie E, Palanza P, Ottinger MA (2007): Effects of xenoestrogens on the differentiation of behaviorally-relevant neural circuits. Front Neuroendocrinol 28, 179-200

Payne JR, Driskell WB, Short JW, Larsen ML (2008): Long term monitoring for oil in the Exxon Valdez spill region. Mar Pollut Bull 56, 2067-81

Péan S, Daouk T, Vignet C, Lyphout L, Leguay D, Loizeau V, Begout ML, Cousin X (2013): Long-term dietary-exposure to non-coplanar PCBs induces behavioral disruptions in adult zebrafish and their offspring. Neurotoxicol Teratol 39, 45-56

Perera FP, Tang D, Wang S, Vishnevetsky J, Zhang B, Diaz D, Camann D, Rauh V (2012): Prenatal polycyclic aromatic hydrocarbon (PAH) exposure and child behavior at age 6-7 years. Environ Health Perspect 120, 921-6

Powers CM, Levin ED, Seidler FJ, Slotkin TA (2011): Silver exposure in developing zebrafish produces persistent synaptic and behavioral changes. Neurotoxicology and Teratology 33, 329-332

Saaristo M, Craft JA, Lehtonen KK, Lindstrom K (2010): Exposure to 17alpha-ethinyl estradiol impairs courtship and aggressive behaviour of male sand gobies (Pomatoschistus minutus). Chemosphere 79, 541-6 
Saili KS, Corvi MM, Weber DN, Patel AU, Das SR, Przybyla J, Anderson KA, Tanguay RL (2012): Neurodevelopmental low-dose bisphenol A exposure leads to early life-stage hyperactivity and learning deficits in adult zebrafish. Toxicology 291, 83-92

Salierno JD, Kane AS (2009): 17alpha-ethinylestradiol alters reproductive behaviors, circulating hormones, and sexual morphology in male fathead minnows (Pimephales promelas). Environ Toxicol Chem 28, 953-61

Saunders CR, Shockley DC, Knuckles ME (2001): Behavioral effects induced by acute exposure to benzo(a)pyrene in F-344 rats. Neurotoxicity research 3, 557-79

Saunders CR, Shockley DC, Knuckles ME (2003): Fluoranthene-induced neurobehavioral toxicity in F-344 rats. International journal of toxicology 22, 263-76

Schmidt K, Staaks GB, Pflugmacher S, Steinberg CE (2005): Impact of PCB mixture (Aroclor 1254 ) and TBT and a mixture of both on swimming behavior, body growth and enzymatic biotransformation activities (GST) of young carp (Cyprinus carpio). Aquat Toxicol 71, 49-59

Scott GR, Sloman KA (2004): The effects of environmental pollutants on complex fish behaviour: integrating behavioural and physiological indicators of toxicity. Aquatic Toxicology 68, 369-392

Shabanov PD, Lebedev AA, Meshcherov Sh K, Strel'tsov VF (2005): The effects of neurochemical lesioning of dopaminergic terminals in early ontogenesis on behavior in adult rats. Neuroscience and behavioral physiology 35, 535-44

Shen $\mathrm{H}$, Huang $\mathrm{Y}$, Wang R, Zhu D, Li W, Shen G, Wang B, Zhang Y, Chen Y, Lu Y, Chen H, Li T, Sun K, Li B, Liu W, Liu J, Tao S (2013): Global atmospheric emissions of polycyclic aromatic hydrocarbons from 1960 to 2008 and future predictions. Environmental science \& technology 47, 6415-6424

Silva CD, Neves AF, Dias AI, Freitas HJ, Mendes SM, Pita I, Viana SD, de Oliveira PA, Cunha RA, Fontes Ribeiro CA, Prediger RD, Pereira FC (2013): A Single Neurotoxic Dose of Methamphetamine Induces a Long-Lasting Depressive-Like Behaviour in Mice. Neurotoxicity research

Soffker M, Stevens JR, Tyler CR (2012): Comparative breeding and behavioral responses to ethinylestradiol exposure in wild and laboratory maintained zebrafish (Danio rerio) populations. Environ Sci Technol 46, 11377-83

Souza BR, Tropepe V (2011): The role of dopaminergic signalling during larval zebrafish brain development: a tool for investigating the developmental basis of neuropsychiatric disorders. Rev Neurosci 22, 107-19

Stacey N (2003): Hormones, pheromones and reproductive behavior. Fish Physiology and Biochemistry 28, 229-235

Steenbergen PJ, Richardson MK, Champagne DL (2011): The use of the zebrafish model in stress research. Prog Neuropsychopharmacol Biol Psychiatry 35, 1432-51

Stewart A, Cachat J, Wong K, Gaikwad S, Gilder T, DiLeo J, Chang K, Utterback E, Kalueff AV (2010): Homebase behavior of zebrafish in novelty-based paradigms. Behav Processes 85, 198-203

Stewart A, Wu N, Cachat J, Hart P, Gaikwad S, Wong K, Utterback E, Gilder T, Kyzar E, Newman A, Carlos D, Chang K, Hook M, Rhymes C, Caffery M, Greenberg M, Zadina $J$, Kalueff AV (2011): Pharmacological modulation of anxiety-like phenotypes in adult zebrafish behavioral models. Prog Neuropsychopharmacol Biol Psychiatry 35, 1421 31

Stewart A, Gaikwad S, Kyzar E, Green J, Roth A, Kalueff AV (2012): Modeling anxiety using adult zebrafish: a conceptual review. Neuropharmacology 62, 135-43

Tang D, Li TY, Liu JJ, Zhou ZJ, Yuan T, Chen YH, Rauh VA, Xie J, Perera F (2008): Effects of prenatal exposure to coal-burning pollutants on children's development in China. Environ Health Perspect 116, 674-9

Timme-Laragy AR, Levin ED, Di Giulio RT (2006): Developmental and behavioral effects of embryonic exposure to the polybrominated diphenylether mixture DE-71 in the killifish (Fundulus heteroclitus). Chemosphere 62, 1097-1104 
Tintos A, Gesto M, Miguez JM, Soengas JL (2008): beta-Naphthoflavone and benzo(a)pyrene treatment affect liver intermediary metabolism and plasma cortisol levels in rainbow trout Oncorhynchus mykiss. Ecotoxicol Environ Saf 69, 180-6

Varanasi U, Casillas E, Arkoosh MR, Hom T, Misitano D, Brown DW, Chan S-L, Collier TK, McCain BB, Stein JE 1993: Contaminant exposure and associated biological effects in juvenile Chinook salmon (Oncorhynchus tshawytscha) from urban and nonurban estuaries of Puget Sound, WA NOAA Fisheries

Vignet C, Begout ML, Pean S, Lyphout L, Leguay D, Cousin X (2013): Systematic screening of behavioral responses in two zebrafish strains. Zebrafish 10, 365-75

Vignet C, Devier MH, Le Menach K, Lyphout L, Potier J, Cachot J, Budzinski H, Bégout M-L, Cousin X (2014a): Long-term disruption of growth, reproduction and behaviour after embryonic exposure of zebrafish to PAHs-spiked sediment. Environmental Science and Pollution Research In press

Vignet C, Le Menach K, Lucas J, Perrichon P, Mazurais D, Le Bihanic F, Lyphout L, Frère L, Bégout M-L, Zambonino-Infante JL, Budzinski H, Cousin X (2014b): Chronic dietary exposure to pyrolytic and petrogenic mixtures of PAHs causes physiological disruption in zebrafish - Part I : Survival and growth. Environmental Science and Pollution Research In press

Xia Y, Cheng S, He J, Liu X, Tang Y, Yuan H, He L, Lu T, Tu B, Wang Y (2011): Effects of subchronic exposure to benzo[a]pyrene (B[a]P) on learning and memory, and neurotransmitters in male Sprague-Dawley rat. Neurotoxicology 32, 188-98

Yanagida GK, Anulacion BF, Bolton JL, Boyd D, Lomax DP, Paul Olson O, Sol SY, Willis M, Ylitalo GM, Johnson LL (2012): Polycyclic aromatic hydrocarbons and risk to threatened and endangered Chinook salmon in the Lower Columbia River estuary. Archives of Environmental Contamination and Toxicology 62, 282-295

Yunker MB, Macdonald RW, Vingarzan R, Mitchell RH, Goyette D, Sylvestre S (2002): PAHs in the Fraser River basin: a critical appraisal of $\mathrm{PAH}$ ratios as indicators of PAH source and composition. Organic Geochemistry 33, 489-515

Zhang Y, Tao S (2009): Global atmospheric emission inventory of polycyclic aromatic hydrocarbons (PAHs) for 2004. Atmospheric Environment 43, 812-819

\section{Figure legends}

Fig. 1 Swimming activity of 6-month-old fish as a function of photoperiod, for each fraction: PY, HO and LO. (a, b, c) Mean distance traveled (cm/30 $\mathrm{min}$ ) averaged per period (day vs. night). (d, e, f) Mean time spent immobile ( $/ 30 \mathrm{~min}$ ) averaged per period (day vs. night). Values are means \pm SEM; $n=12$ fish per fraction and concentration; * indicates a significant difference at $p<0.05$.

Fig. 2 Photomotor response of 2-month-old fish, for each fraction: PY, HO and LO. (a, c, e) Distance traveled $(\mathrm{cm} / \mathrm{min})$ over one hour, before a 15-min lights-off period (gray shadowing) followed by an additional $1.5 \mathrm{~h}$ of monitoring. The superimposed view shows the distance traveled summed per 15-minute period before, during and after the lights-off period. (b, $d, f)$ Time spent immobile (s/15 min) per 15-minute period before, during and after the lights-off period. Values are means \pm SEM; $n=12$ fish per fraction and concentration; * indicates a significant difference at $\mathrm{p}<0.05$.

Fig. 3 Maze exploration by 2-month-old fish for each fraction: PY, HO and LO. (a) Time (s) to first exit from the start area in the T-maze (PY fraction). (b, c) Time (s) to first exit from the start area in the Z-maze (HO and LO fractions, respectively). Values are means \pm SEM; $n=12$ fish per fraction and concentration; different letters indicate significant differences at $p<0.05$. 
Fig. 4 Maze exploration by 2-month-old fish for each fraction: PY, HO and LO. (a) Total time spent (s) in the start, shallow and deep areas of the T-maze (PY fraction). (b, c) Total time spent (s) in the start, close and distant areas of the Z-maze ( $\mathrm{HO}$ and LO fractions, respectively). Values are means \pm SEM; $n=12$ fish per fraction and concentration; different letters indicate significant differences at $p<0.05$.

Fig. 5 Maze exploration by 2-month-old fish for each fraction: PY, HO and LO.(a) Proportion of individuals successfully reaching the deep zone of the T-maze or the farthest quadrant (16) of the $Z$ maze. (b) Time (s) to first entry into the deep area of the T-maze (PY) or the farthest quadrant of the Z-maze (HO, LO). (c) Proportion of Z-maze explored in HO and LO fish. Values are means \pm SEM; the numbers of fish reaching the deep area or quadrant 16 per fraction and concentration are indicated on the bars; different letters indicate significant differences at $p<0.05$.

Fig. 6 Novel tank challenge in 2-month-old fish for each fraction: PY, HO and LO. (a, d, g) Mean time spent (s) per minute (Min-1 to Min-6) in the top area of the novel tank. (b, e, h) Total distance traveled $(\mathrm{cm})$ over the 6-minute challenge. (c, $\mathrm{f}, \mathrm{i})$ Total time spent immobile (s) over the 6-minute challenge. Values are means \pm SEM; $n=12$ fish per fraction and concentration; different letters and * indicate significant differences at $p<0.05$. 
Figure 1

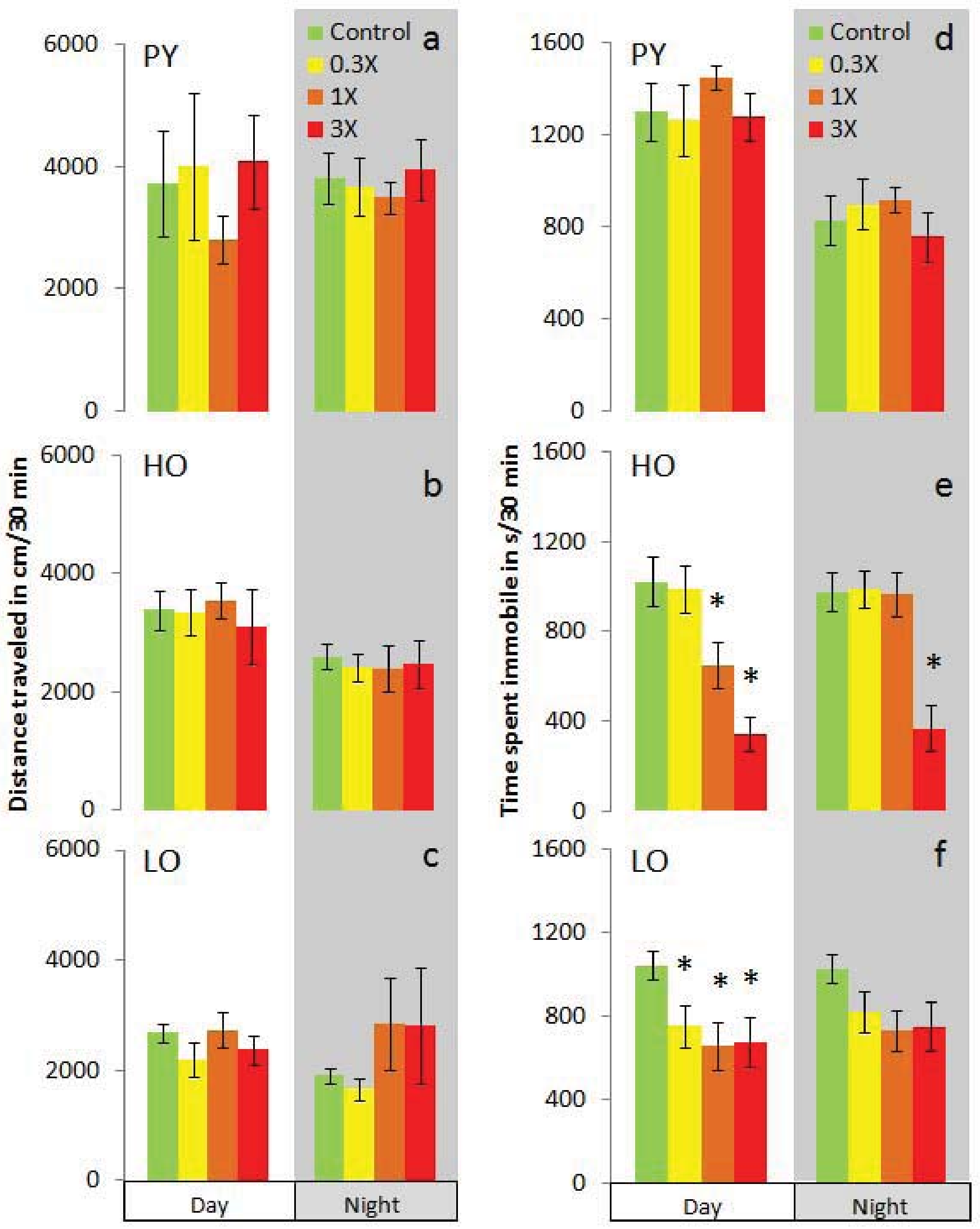


Figure 2
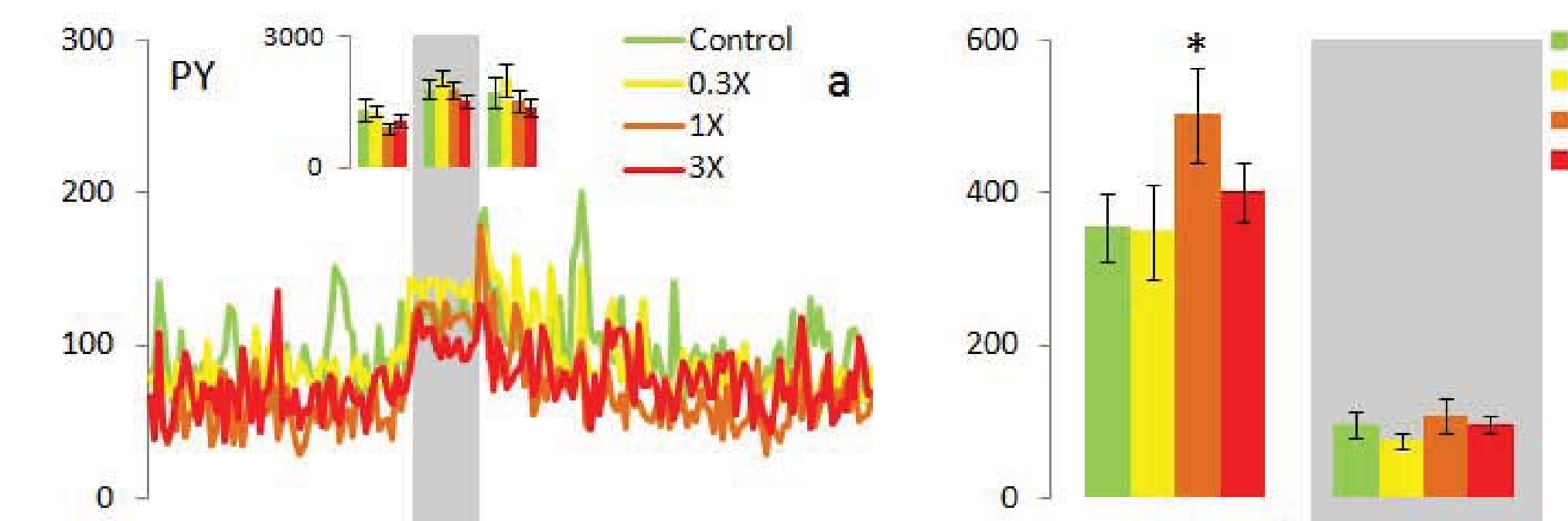

Control

$0.3 \mathrm{X}$

= $1 \mathrm{x}$

ㅁ $3 \mathrm{X}$
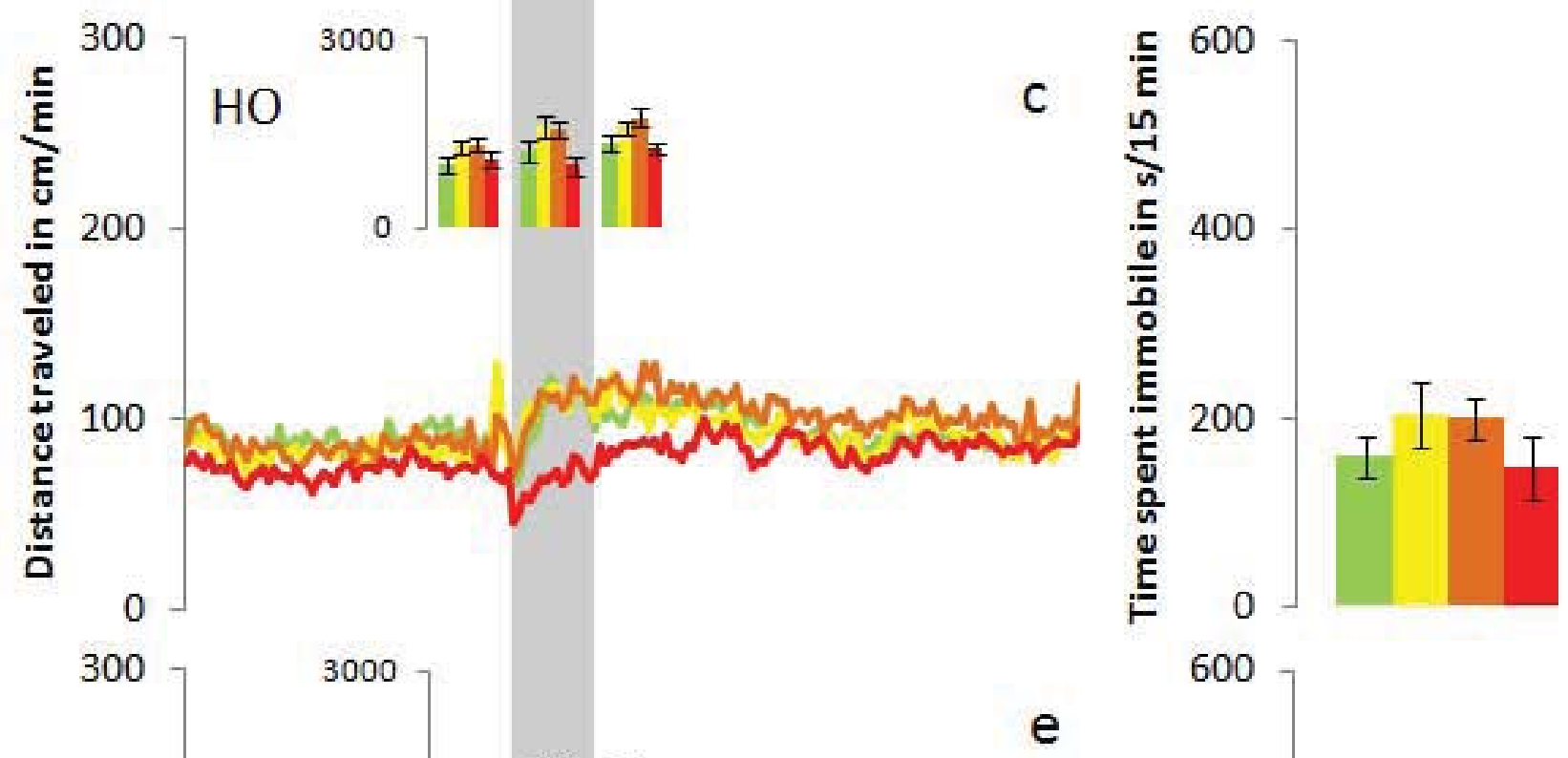

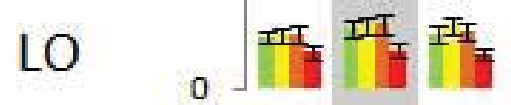

200
100

0

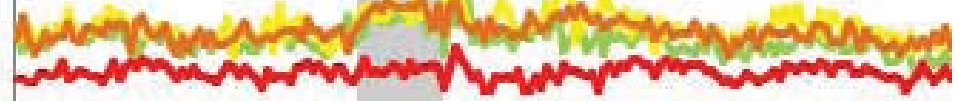

Light on-1

off

Light on-2 d

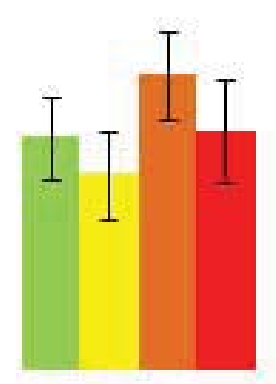

f

0

Light on-1

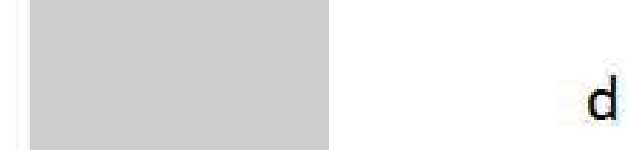

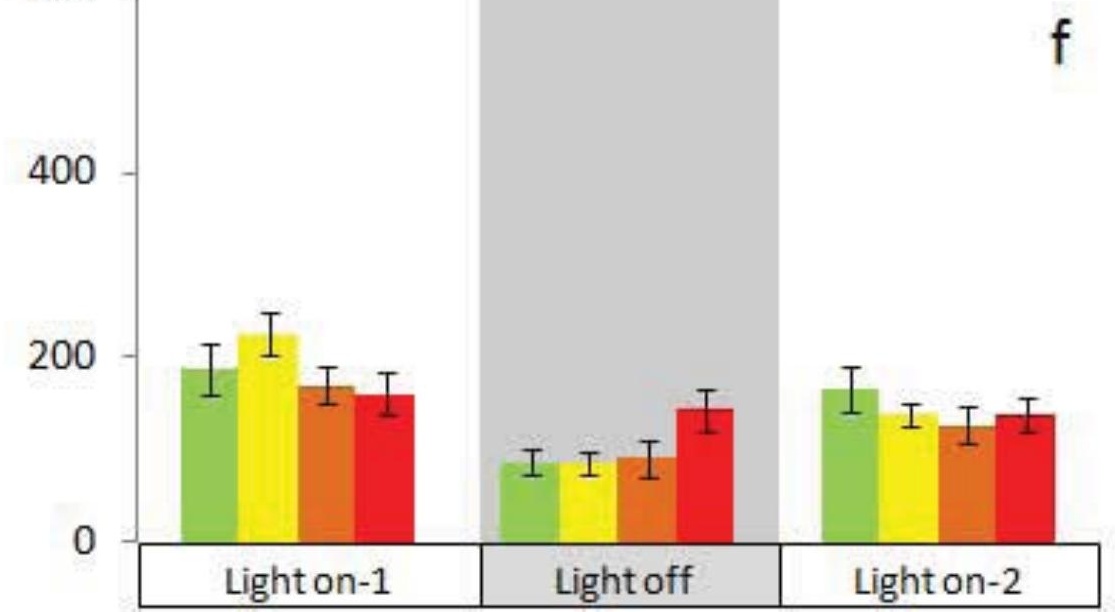


Figure 3

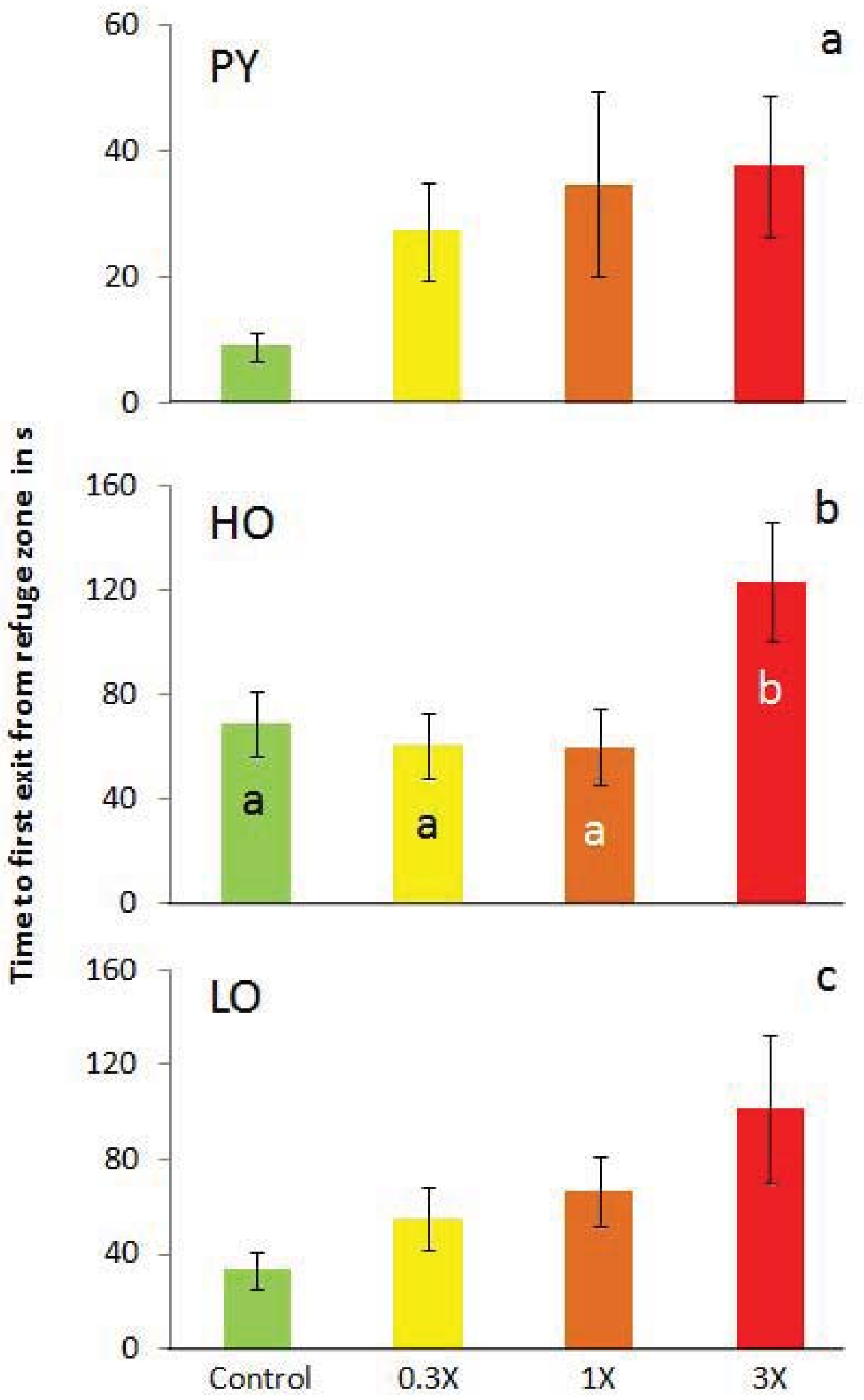


Figure 4

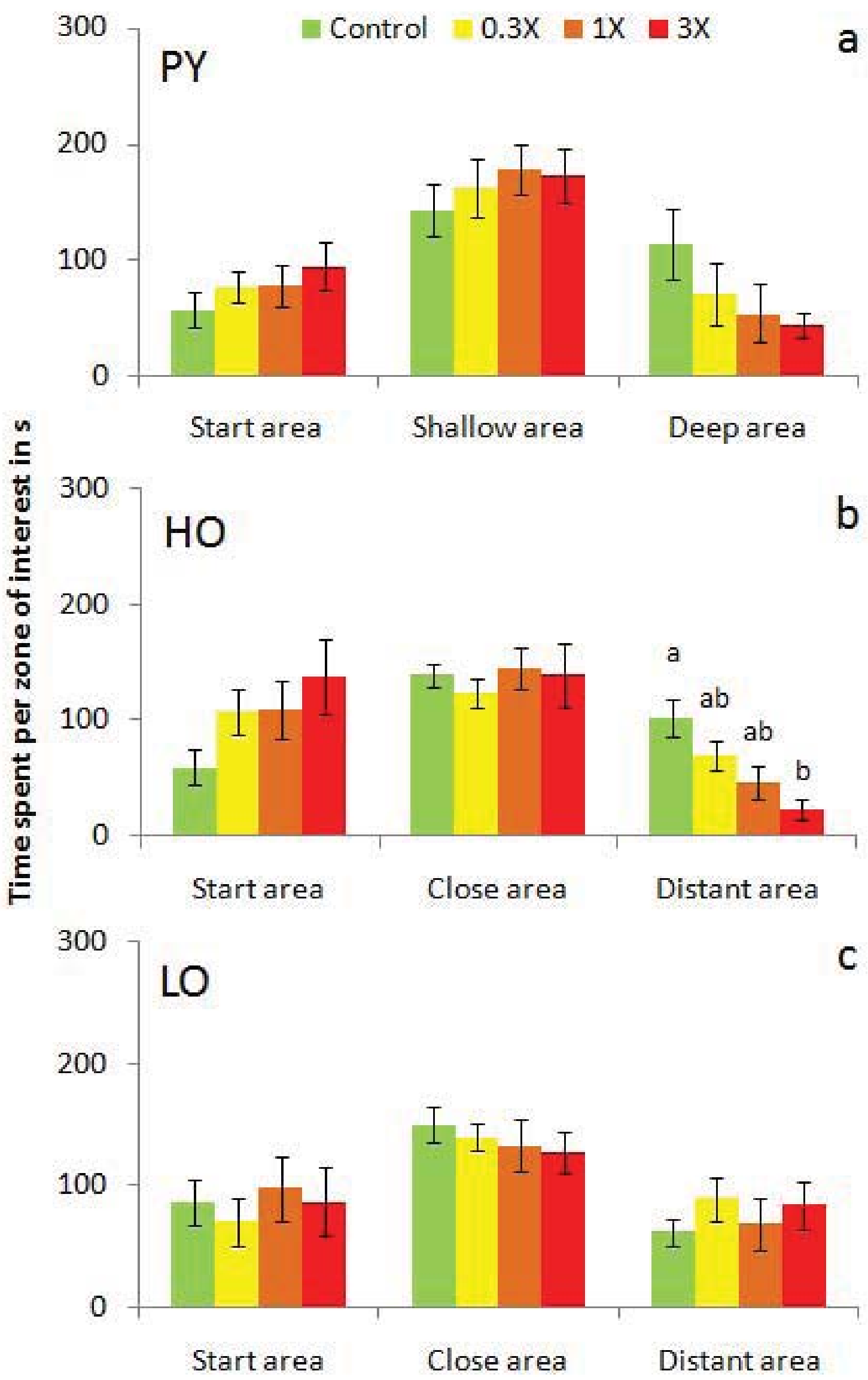


Figure 5

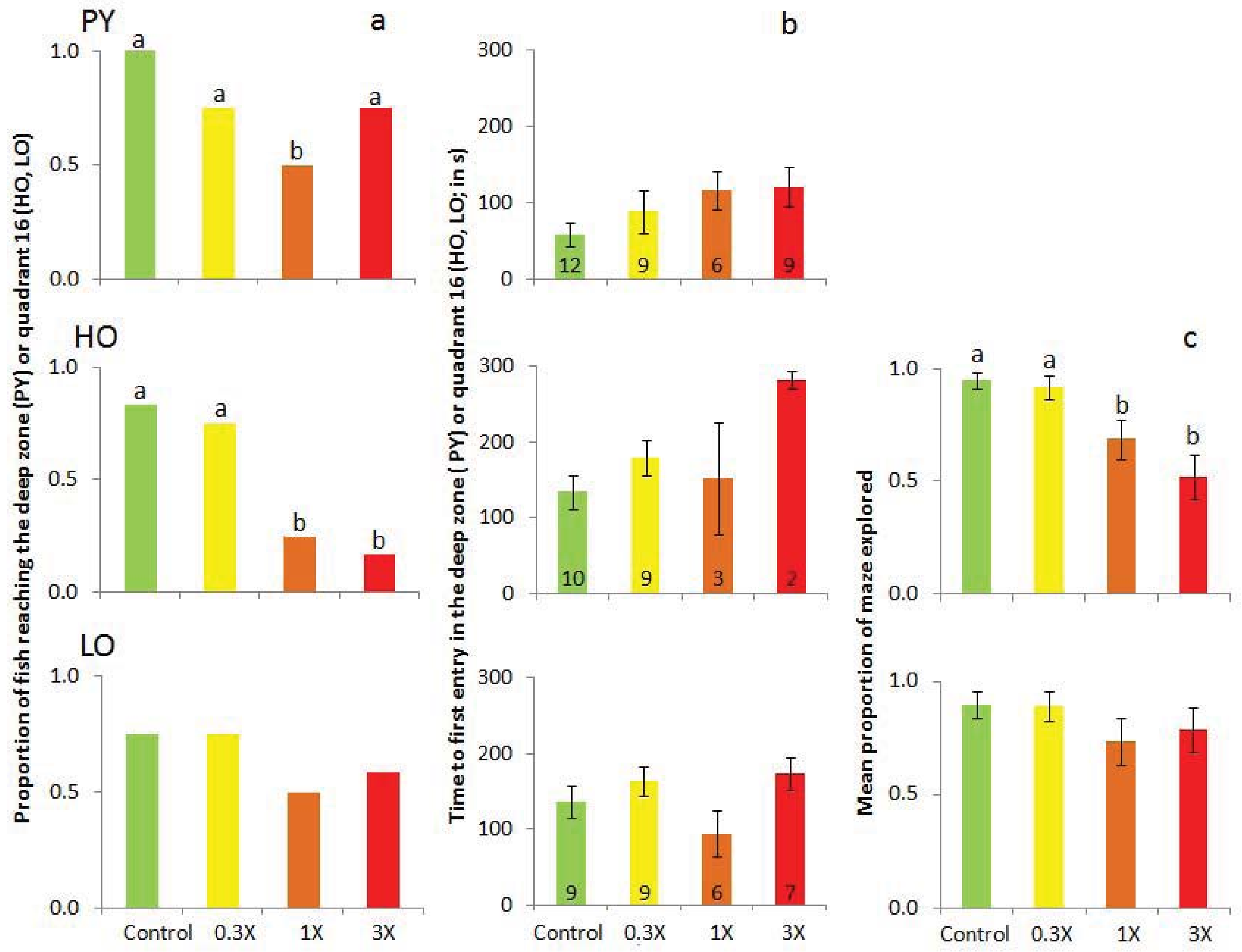


Figure 6

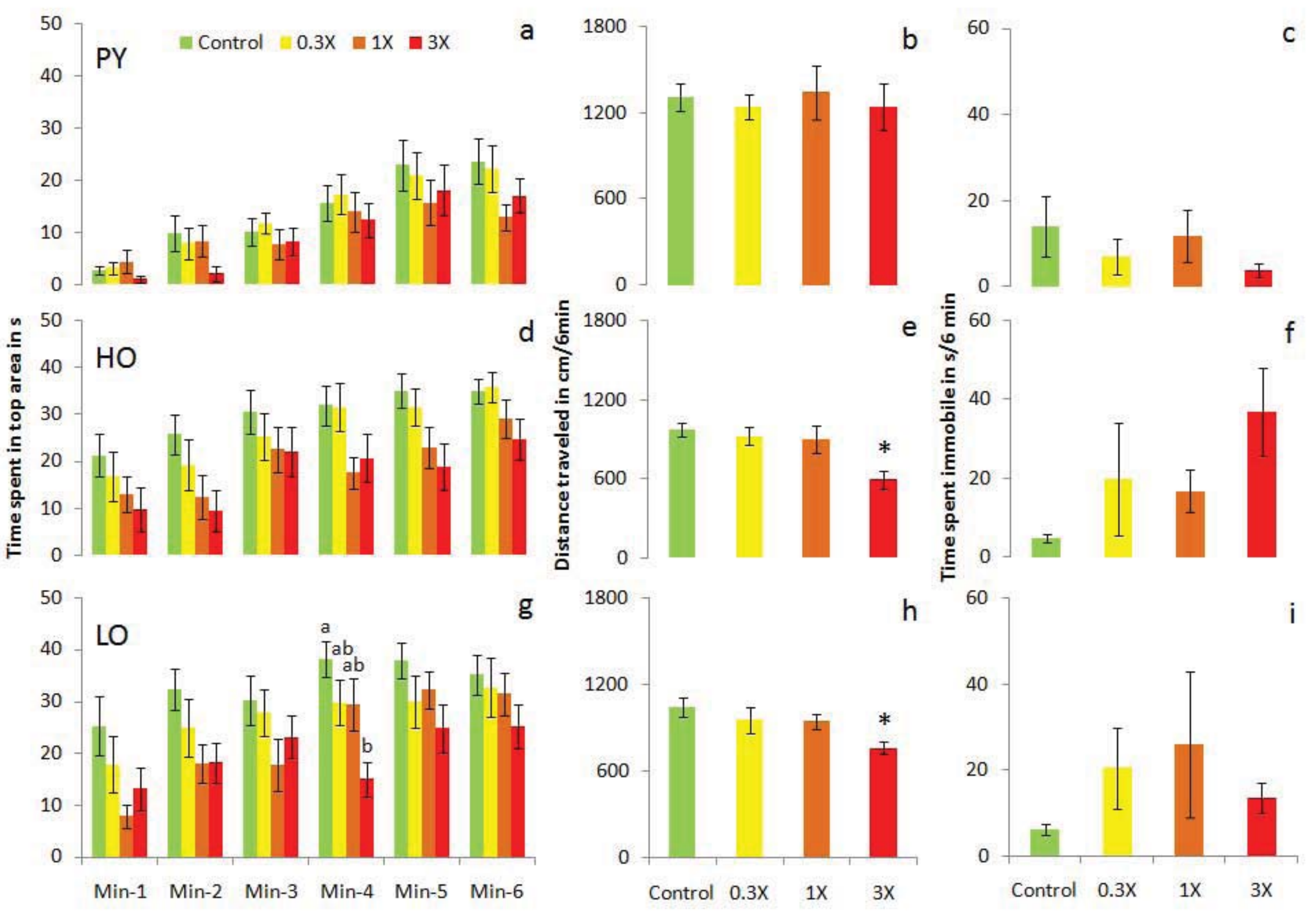

